\title{
Erratum to: Rooting Around the Eutherian Family Tree: the Origin and Relations of the Taeniodonta
}

\author{
Deborah L. Rook • John P. Hunter
}

Published online: 3 October 2013

(C) Springer Science+Business Media New York 2013

\section{Erratum to: J Mammal Evol \\ DOI 10.1007/s10914-013-9230-9}

The original version of this article contained some errors having to do with character coding, character state assignments for some taxa, and character definitions. Discovery of these errors requires changes to our character matrices and reanalysis, as we detail below.

In the characters used to test the cimolestan ancestry of taeniodonts (Appendix 1), an asterisk indicating additive characters is required for character 2 and 23. The states of character 2 should be rearranged from small (0), large (1), and absent (2) to absent (0), small (1), and large (2), with changes accordingly to the matrix. In the characters used to test membership of taeniodonts in the eutherian crown group (Appendix 2), the state of characters 10,14 , and 133 are unknown in Schowalteria and therefore should not be coded in the taxon. For Schowalteria, character 22 should be coded as " 0 " and character 69 should be "2" for Schowalteria and Alvengena. Reanalysis using a revised matrix (Appendix 1) returned a single most parsimonious tree from 7,388,776 trees with a length of 191, CI of 0.30, and RI of 0.62. Bremer support

The online version of the original article can be found at http://dx.doi.org/ 10.1007/s10914-013-9230-9.

\section{L. Rook}

Department of Evolution, Ecology, and Organismal Biology, Ohio

State University, Columbus, OH 43210, USA

J. P. Hunter

Department of Evolution, Ecology and Organismal Biology, Ohio

State University- Newark, Newark, OH 43055, USA

Present Address:

D. L. Rook $(\square)$

Department of Geoscience, University of Wisconsin-Madison,

Madison, WI 53706, USA

e-mail: drook@wisc.edu values for the first analysis have changed, but the overall topology and conclusions have not. The clade containing Didelphodus has a support of 2 (up from 1) with Aaptoryctes and Palaeoryctes supported by 3 (up from 1), while the clade containing the cimolestids and taeniodonts has a support of 4 (up from 1). Within the taeniodonts, the clade containing Onychodectes and that containing Schochia each have a support of 1 (down from 2), while the clade containing Psittacotherium is supported by 4 (up from 3). Conoryctes and Huerfandon (which should be Huerfanodon) are supported by 2 (up from 1), and Ectoganus and Stylinodon by 7 (up from 6).

Reanalysis using a revised Appendix 2 resulted in three most parsimonious trees from $170,862,118$ trees examined with a length of 2627 , CI of 0.22 , and RI of 0.47 . The new second analysis, though the topology is unchanged, returned a Bremer support of 3 (down from 4) for Alveugena+ Schowalteria.

Finally, for completeness, we mention that Robertschochia Lucas, 2011, is currently the valid name for Schochia. We thank Dr. Richard Fox for bringing to our attention errors having to do with the coding of Schowalteria. 